\title{
Leveling with Step Potential in Damascene Cu Electrodeposition
}

\author{
Sung Ki Cho and Jae Jeong Kim*,z
}

Research Center for Energy Conversion and Storage, School of Chemical and Biological Engineering, Seoul National University, Shillim-dong, Kwanak-gu, Seoul 151-742, Korea

\begin{abstract}
Organic leveler-free leveling, issued in damascene $\mathrm{Cu}$ electrodeposition for uniform $\mathrm{Cu}$ patterning by the chemical mechanical polishing process, was investigated using a potentiostatic step function. A perfectly leveled $\mathrm{Cu}$ surface was obtained with applying a positive step potential. The distribution of locally adsorbed bis(3-sulfopropyl disulfide (SPS), which was the main cause of the formation of topographic variation on the wafer surface, was modified by the use of a positive step potential. The redistribution of adsorbed SPS was a result of desorption of SPS through the dissolution occurring during the step time. Desorbed SPS was then readsorbed uniformly on the $\mathrm{Cu}$ surface after a step time, resulting in a flat $\mathrm{Cu}$ surface. Electrochemical linear sweep voltammetry and chronoamperometry analyses revealed a decrease in current, which meant the desorption of SPS on Cu surface was caused by the dissolution of $\mathrm{Cu}$. By varying the step potential and step time, it was confirmed that at least $6 \mathrm{~nm}$ of the $\mathrm{Cu}$ layer should be dissolved for effective desorption of SPS and successful leveling.

(c) 2006 The Electrochemical Society. [DOI: 10.1149/1.2354459] All rights reserved.
\end{abstract}

Manuscript submitted April 27, 2006; revised manuscript received July 13, 2006. Available electronically October 9, 2006.

Organic additive, especially accelerator, plays a key role in superfilling in the process of damascene $\mathrm{Cu}$ electrodeposition. Geometrically induced local accumulation of the accelerator is regarded as the most appropriate explanation for the phenomenon of superfilling. ${ }^{1-3}$ However, because the degree of accumulation of accelerator depends on pattern density and size, ${ }^{4}$ uneven deposition takes place according to the adsorbed amount of accelerator, leading to topographic variations throughout the wafer. This variation causes the nonuniform definition of the $\mathrm{Cu}$ interconnects in the CMP process. ${ }^{5,6}$ Therefore, leveling as well as superfilling in the electrodeposition procedure is required for high device yield in the manufacturing process.

Studies investigating leveling in damascene electrodeposition have only been initiated recently. A few leveling methods have been proposed either practically or conceptually. ${ }^{5-12}$ Among them, the use of organic levelers, ${ }^{7-9}$ with heterocyclic structures containing $\mathrm{O}, \mathrm{N}$, and $\mathrm{S}$ atoms, is most common. Some leveling procedures with organic leveler in combination with suppressor and accelerator have been evaluated in the papers and patents. ${ }^{6,10-12}$ However, the high sulfur and nitrogen incorporation and the decomposition of leveler cause an abrupt increase in resistivity. ${ }^{13}$ Moreover, additional additive causes the difficulties in controlling the electrolyte condition.

Leveler-free leveling, developed in this study, is based on the control of the applied potential and current. There are some indications of the possibility and feasibility for a leveler-free leveling method. The adsorption and activation of organic additives are related to the electrical potential and surface reaction at the electrode. ${ }^{5,14,15}$ Moffat et al. ${ }^{16}$ have recently reported the deactivation of the conventional accelerator, bis(3-sulfopropyl) disulfide (SPS), at the overpotential of $-50 \mathrm{mV}$. These imply the distribution of the adsorbed accelerator can be modified by changing the applied potential or current. Ultimately, leveling is feasible through applying a multistep potentiostatic or galvanostatic step function during electrodeposition. Although use of an additional organic additive is not necessary and process variables are easily controlled with this leveling process, outstanding achievement has yet to be obtained.

In this study, we present successful leveling with the step potential and suggest a mechanism of leveling through electrochemical analyses.

\section{Experimental}

The substrate used in this study was a trench-type single damascene (with a linewidth of $130 \mathrm{~nm}$ and an aspect ratio of 2) Si wafer with a structure of physical vapor deposition (PVD) $\mathrm{Cu}(60 \mathrm{~nm}) /$ PVD Ta $(7.5 \mathrm{~nm}) /$ PVD TaN $(7.5 \mathrm{~nm}) / \mathrm{Si}$.

* Electrochemical Society Active Member.

z E-mail: jjkimm@snu.ac.kr
The electrolyte was composed of $0.25 \mathrm{M} \mathrm{CuSO}_{4} \cdot 5 \mathrm{H}_{2} \mathrm{O}, 1 \mathrm{M}$ $\mathrm{H}_{2} \mathrm{SO}_{4}$, and deionized (DI) water with the addition of $88 \mu \mathrm{M}$ poly(ethylene glycol) (PEG, Mw 3400), $1 \mathrm{mM} \mathrm{NaCl}$, and $50 \mu \mathrm{M}$ SPS (Raschig GmbH, Germany) for superfilling in the damascene structure. ${ }^{17} \mathrm{Cu}$ electrodeposition was conducted in this electrolyte using the three-electrode system with a $99.9 \% \mathrm{Cu}$ wire as a counter electrode, and a saturated calomel electrode (SCE) as a reference electrode. The electrodeposition area was $1 \mathrm{~cm}^{2}$. Electrolyte agitation was not performed during electrodepositon.

Figure 1 shows a potentiostatic step function applied during leveling. The total electrodeposition procedure was classified into the three phases, as shown in Fig. 1. During the first phase, a constant potential of $-250 \mathrm{mV}$ was applied for $20 \mathrm{~s}$ in order to superfill the trenches. At this point, considerable topographic variation had not been generated yet. During the second phase, a step potential was applied to deactivate or desorb the adsorbed accelerator. Finally, during the third phase, the constant potential of $-250 \mathrm{mV}$ was applied for the further deposition. These three phases were carried out continuously through the step function generated by a PAR 263 (EG\&G Princeton Applied Research Corporation) potentiostat. The step time, the period of time that the step potential was applied, was $3 \mathrm{~s}$ and the step potentials were in the range of -100 to $200 \mathrm{mV}$ (vs $\mathrm{SCE})$.

In order to analyze the effect of the step potential, electrochemical analyses were performed with a $\mathrm{Cu}$ rotating disk electrode (RDE) whose electrode area and rotating speed were $0.2 \mathrm{~cm}^{2}$ and $300 \mathrm{rpm}$, respectively. Chronoamperometry was conducted with triple-step potentiostatic step functions, the same as those used in leveling. Linear sweep voltammetry (LSV) was also carried out with specific electrochemical pretreatment. Before a potential sweep, $\mathrm{Cu}$ was electrodeposited on RDE with PEG-Cl-SPS for $20 \mathrm{~s}$. The criti-

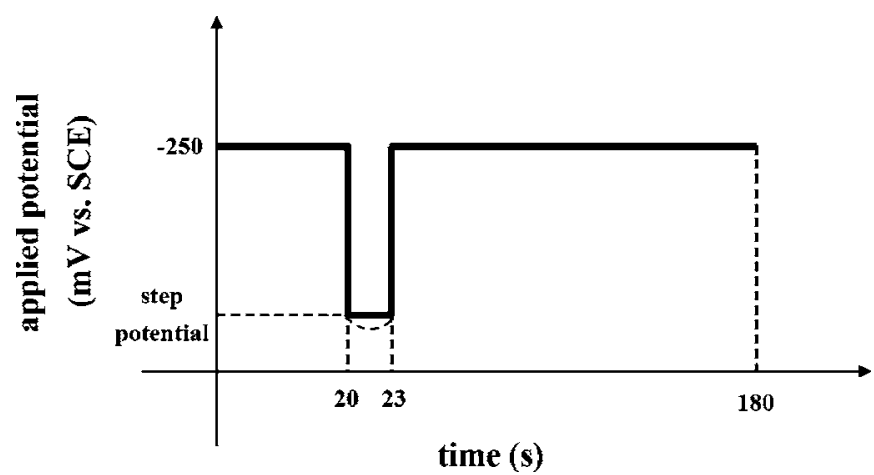

Figure 1. The potentiostatic step function applied on the substrate during electrodeposition for leveling. 

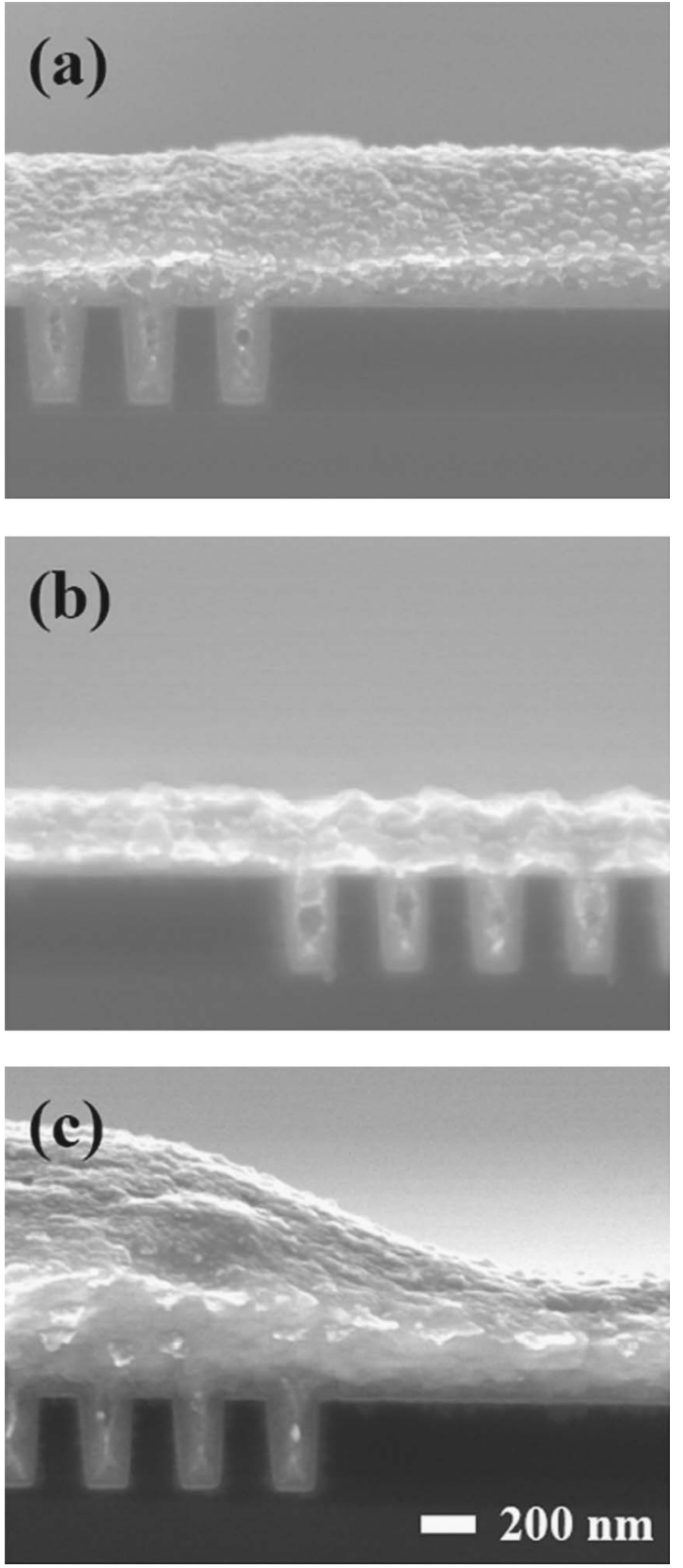

Figure 2. Cross-sectional FESEM images of $\mathrm{Cu}$ electrodeposited with a constant potential of $-250 \mathrm{mV}$ (vs SCE) in the electrolyte containing (a) no additive, (b) PEG-Cl, and (c) PEG-Cl-SPS.

cal potentials, which were equal to the absolute values of the step potentials, were applied successively for $3 \mathrm{~s}$ in PEG-Cl electrolyte, that is, the electrolyte containing only PEG and chloride ion. After this pretreatment, linear sweep voltammetry (LSV) was performed in PEG-Cl electrolyte. The scan rate was $10 \mathrm{mV} / \mathrm{s}$ in the range of 50 to $-800 \mathrm{mV}$. By using these successive pretreatments, the characteristics of the RDE surface were similar to those of the $\mathrm{Cu}$ wafer at the end of the step time during leveling. The use of SPS-free electrolyte prevented the diffusion of SPS from bulk electrolyte to the RDE surface. A field emission scanning electron microscope (FESEM, JEOL, JSM-6330F) was used to investigate the profiles of the electrodeposited $\mathrm{Cu}$.

\section{Results and Discussion}

Figure 2 shows the cross-sectional images of $\mathrm{Cu}$ films electrode-
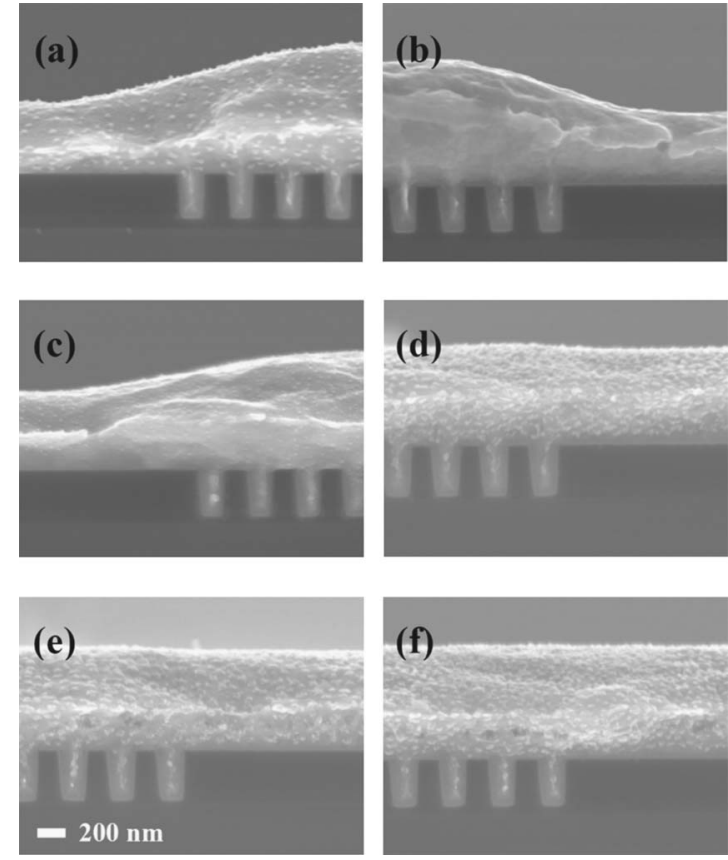

Figure 3. Cross-sectional FESEM images of $\mathrm{Cu}$ electrodeposited with the step potentials of (a) -100, (b) -50, (c) 50, (d) 100, (e) 150, and (f) $200 \mathrm{mV}$ (vs SCE), respectively.

posited using varying electrolyte compositions without the step potential (with a constant potential of $-250 \mathrm{mV}$ (vs SCE) which caused the current density to be in the range of $\left.5-30 \mathrm{~mA} / \mathrm{cm}^{2}\right)$. Due to the absence of the accelerator, the topographic variation as well as superfilling were not formed in the additive-free electrolyte and PEG-Cl electrolyte (Fig. 2a and b). When the accelerator was added in the electrolyte, a topographic variation of $550 \mathrm{~nm}$ was generated by applying the constant potential for $180 \mathrm{~s}$ (Fig. 2c). It is certain that SPS is solely responsible for the formation of topographic variation. Generally, the uniformity of the deposit depends on additive chemistry and active surface area per unit area, especially with the pattern scale. ${ }^{4,18}$ Considering that there was no difference in deposits between the patterned and nonpatterned areas (Fig. 2a and b), it was concluded that the effect of surface area was negligible on the formation of topographic variations in these experiments.

Figure 3 exhibits the topographic variations formed using the various step potentials. The step potential of $-100 \mathrm{mV}$ did not suppress the formation of variation (Fig. 3a). As the step potential increased positively, the variations were reduced as a result of a decrease in the reduction current during the step time (Fig. $3 b$ and c). Finally, an almost flat $\mathrm{Cu}$ surface, on patterned and nonpatterned regions, was obtained using a step potential higher than $100 \mathrm{mV}$ (Fig. 3d-f). The remarkable phenomenon was that successful leveling could only be achieved when large dissolution currents of $\mathrm{Cu}$ were generated during the step time, though the overall current densities during electrodeposition were not changed with the step potentials. (They were in the range of $8-25 \mathrm{~mA} / \mathrm{cm}^{2}$, the same as that without step potential.) The current of each step potential generated during the step time is shown in Fig. 4. The dissolution current was observed with the positive step potential of 50,100, 150, and $200 \mathrm{mV}$. Assuming uniform current distribution and $100 \%$ current efficiency, each dissolution thickness can be calculated by Faraday's law

$$
h=\frac{M}{n F A d} \int i d t
$$

where $h$ is the dissolution thickness, $M$ is the molecular weight of $\mathrm{Cu}, A$ is the electrode area, $F$ is the Faraday constant, $i$ is the cur- 


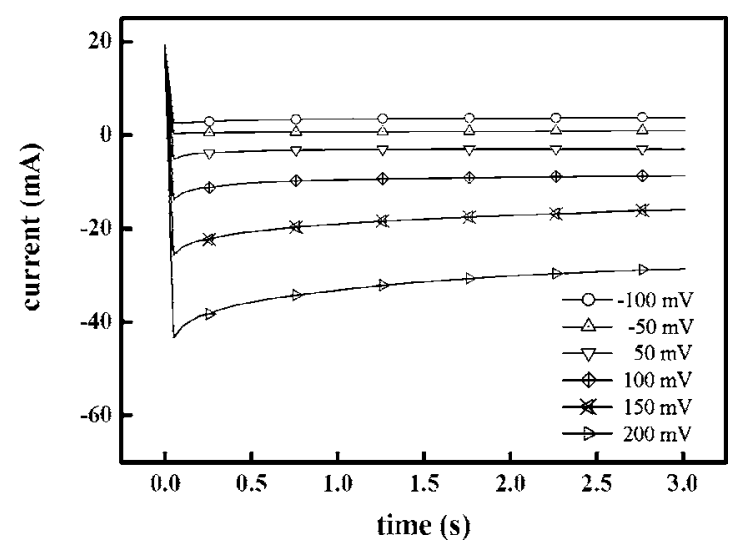

Figure 4. Current-time curves during the step time according to the step potentials.

rent, $d$ is the density of $\mathrm{Cu}$, and $n$ is the number of electrons needed to reduce the cupric ion to $\mathrm{Cu}$. The dissolution thicknesses of the step potentials of $50,100,150$, and $200 \mathrm{mV}$ were $3.4,10.4,20.2$, and $35.3 \mathrm{~nm}$, respectively, which were too small to make a considerable reduction in deposition thickness. Figure 5 shows the $\mathrm{Cu}$ profiles before and after applying the positive step potentials. Just before the step time, trenches were filled completely with the formation of bumps (Fig. 5a). The following step reduced the $\mathrm{Cu}$ thickness due to $\mathrm{Cu}$ dissolution by the positive step potentials during the step time. However, the $\mathrm{Cu}$ profiles after the step time were almost identical to those before the step time (Fig. 5b-d). That is, the dissolution by the positive step potential did not change the topology, as expected numerically, though it caused big differences in the final profile.

Since the formation variations were related to the function of adsorbed accelerator, and the change in topology by dissolution was negligible, it could be deduced that the desorption of SPS by dissolution has a profound effect on leveling. The dissolution might remove the locally accumulated SPS and cause SPS to readsorb uni-
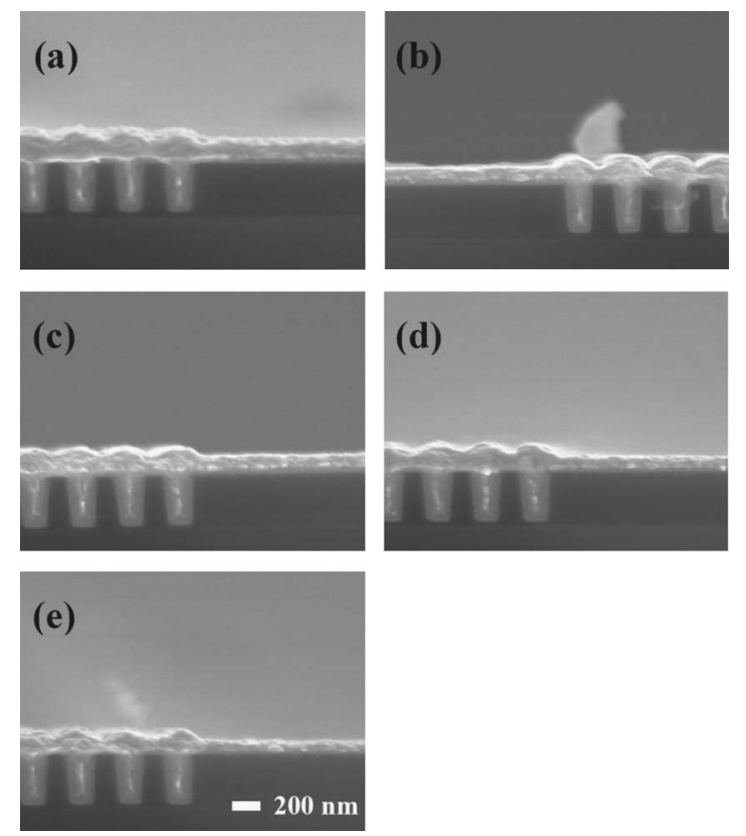

Figure 5. Cross-sectional FESEM images of $\mathrm{Cu}$ (a) before applying the step potential and after applying the step potentials of (b) 50, (c) 100, (d) 150, and (e) $200 \mathrm{mV}$ (vs SCE), respectively.
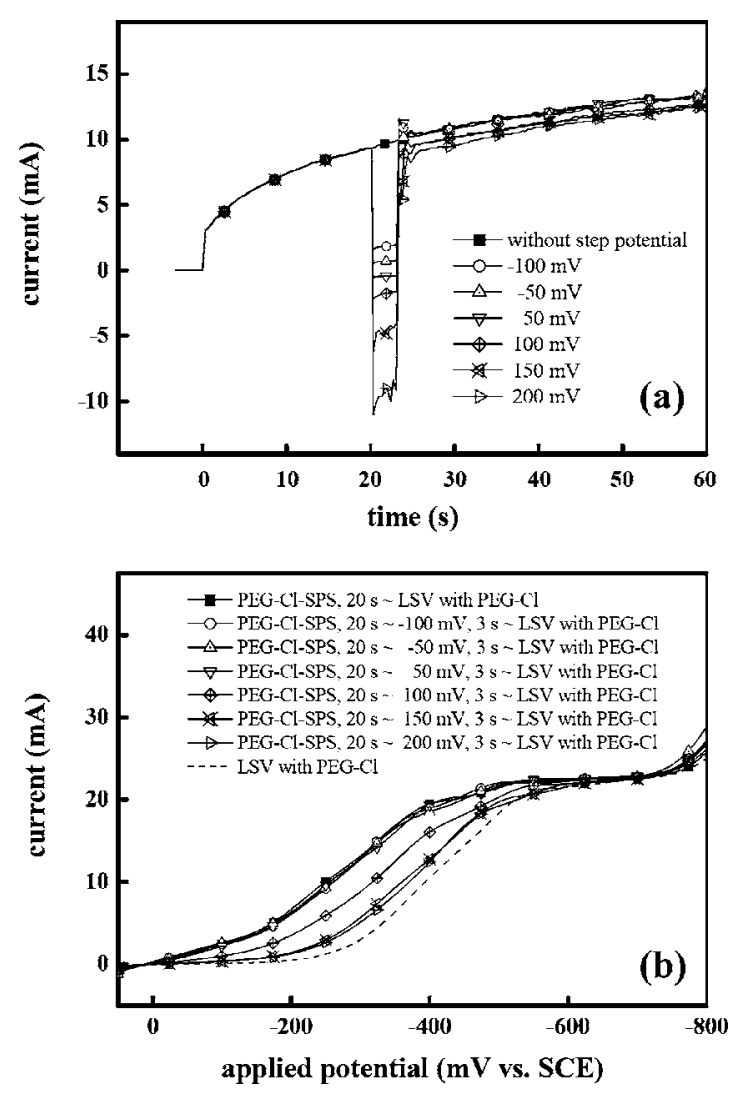

Figure 6. (a) Potential step chronoamperometry on RDE for various step potentials. (b) LSV on pretreated RDE in the PEG-Cl electrolyte. The pretreatment was composed of two steps. The first step was electrodeposition with PEG-Cl-SPS for $20 \mathrm{~s}$. The second step was applying the critical potentials with the range of -100 to $200 \mathrm{mV}$ (vs SCE) for $3 \mathrm{~s}$ with PEG-Cl electrolyte.

formly on the $\mathrm{Cu}$ surface. That is to say, the step potential might modify the local distribution of adsorbed SPS and make uniform $\mathrm{Cu}$ deposition possible. Although the step potential of $50 \mathrm{mV}$ also made the dissolution for the $3 \mathrm{~s}$ period, it failed in leveling. This may be due to its dissolution thickness of $3.4 \mathrm{~nm}$, which may not be sufficient for the desorption of SPS.

The desorption of SPS by dissolution was observed with the electrochemical analyses. Figure 6a shows potential step chronoamperometry with the potentiostatic step function used in leveling. The current on RDE without the step potential increased gradually due to the adsorption of SPS by the competition with suppressor, that is, PEG-Cl. ${ }^{, 3}$ The application of the step potentials of -100 , -50 , and $50 \mathrm{mV}$ did not cause changes in current, indicating that the amounts of adsorbed SPS were not affected by those step potentials. However, when considerable dissolution occurred during the step time with the step potentials higher than $100 \mathrm{mV}$, the current responses decreased immediately after the step times. That is to say, the dissolution during the step time with a positive step potential reduced the amount of adsorbed SPS, and consequently, reduced the current.

LSV on RDE was also performed in order to analyze the effect of dissolution on the adsorption of SPS (Fig. 6b). The RDE surface was pretreated before sweeping the potential in order to create the similar characteristics of the RDE surface with those of $\mathrm{Cu}$ wafer at the end of the step time. The first pretreatment of electrodeposition with SPS led to the adsorption of SPS on the RDE surface. The second pretreatment of applying the critical potential was expected to desorb SPS, which was adsorbed during the first pretreatment. Compared to a fresh RDE surface, the RDE surface which had only the first pretreatment showed a large current due to adsorbed SPS. When 


\section{step potential}

$50 \mathrm{mV}$
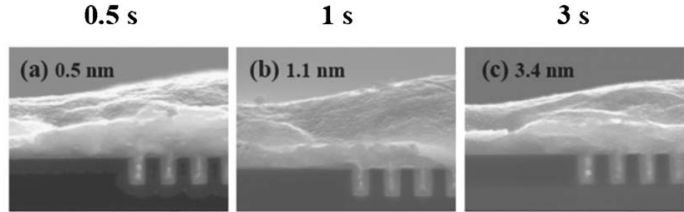

$100 \mathrm{mV}$
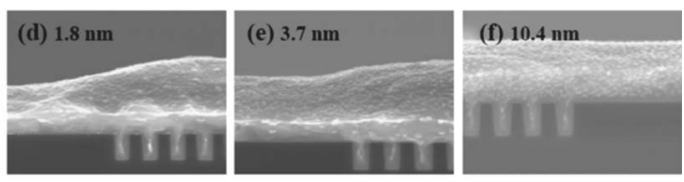

$150 \mathrm{mV}$
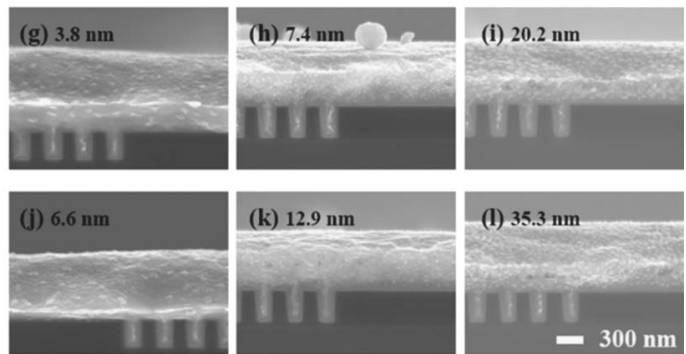

Figure 7. Cross-sectional FESEM images of $\mathrm{Cu}$ electrodeposited with the various step potentials and step times. The step potentials were $(\mathrm{a}-\mathrm{c}) 50$, (d-f) 100, (g-i) 150, and (j-1) $200 \mathrm{mV}$ (vs SCE), respectively. The step times used were $0.5,1$, and $3 \mathrm{~s}$ at each step potential. The value marked in each figure corresponds to each dissolution thickness during the step time.

the critical potentials from -100 to $50 \mathrm{mV}$ were applied at the second pretreatment, currents were almost similar to those obtained without the second pretreatment. This indicated that those second pretreatments did not have any effect on adsorbed SPS. However, the critical potentials of 100,150 , and $200 \mathrm{mV}$, which created the dissolution current at the second pretreatment, led to the current decreases in LSV. These were related to the reduction in the amount of adsorbed SPS. Additionally, increasing the applied critical potential resulted in an increase of desorbed SPS, since the dissolution occurred more severely as the critical potential became more positive.

Based on the desorption of SPS by dissolution, the leveling phenomena could be clearly explained. Through an initial superfilling, SPS was locally accumulated on the trench top surface with the formation of bumps. Adsorbed SPS was then removed through the dissolution of the $\mathrm{Cu}$ surface layer during the step time with the positive step potential. Subsequently, it adsorbed again uniformly on the nonpatterned $\mathrm{Cu}$ surface regions as well as patterned regions immediately after the step time. Therefore, after that, the deposition occurred uniformly on patterned and nonpatterned regions.

The step potential of $50 \mathrm{mV}$ did not affect the adsorption of SPS in all analyses, even though it caused a dissolution current. This may be due to the lack of sufficient dissolution thickness to remove the adsorbed SPS. The relation between the dissolution thickness and the desorption became clear with the control of both the step potential and step time. Figure 7 shows the cross-sectional images of $\mathrm{Cu}$ electrodeposited with the various step potentials and step times. The value marked in each figure represents the dissolution thickness during each step time. As the step time decreased, the critical step potential which could make a leveled $\mathrm{Cu}$ surface shifted to a more positive value at each step time (Fig. $7 f, h$ and $j$ ). The successful leveling was achieved with a dissolution thickness of more than about $6 \mathrm{~nm}$ during the step time (Fig. 7f, h-1). More than $6 \mathrm{~nm}$ of $\mathrm{Cu}$ layer should be dissolved to remove the adsorbed SPS effectively. Actually, the removal of one monolayer of $\mathrm{Cu}$ surface was enough for the desorption of adsorbed SPS. However, SPS could be readsorbed or might not be fully desorbed during step time. Therefore, the removal of more than one monolayer of $\mathrm{Cu}$ might be necessary for the sufficient desorption of SPS. It is difficult to understand the physical meaning of the dissolution thickness, $6 \mathrm{~nm}$, because it is related to the dissolution rate of the $\mathrm{Cu}$ surface, surface concentration of SPS, desorption/readsorption rate of SPS, and so on. Nevertheless, it is significant that the criterion for the successful leveling was a dissolution thickness of at least $6 \mathrm{~nm}$ during the step time rather than the value of the step potential.

\section{Conclusions}

Electrodeposition with a constant potential of $-250 \mathrm{mV}$ generated a topographic variation of about $550 \mathrm{~nm}$ in the PEG-Cl-SPS electrolyte system. The use of a potentiostatic step function with the positive step potentials of 100,150 , and $200 \mathrm{mV}$ produced an almost flat $\mathrm{Cu}$ surface. The dissolution currents with the step potentials of 100,150 , and $200 \mathrm{mV}$ desorbed the locally accumulated SPS and caused SPS to readsorb uniformly on the $\mathrm{Cu}$ surface, allowing the uniform deposition. The decrease in current of chronoamperometry and LSV indicated the desorption of SPS by the dissolution current during the step time and pretreatment. Electrodeposition with the various step potentials and step times showed that the dissolution of more than $6 \mathrm{~nm}$ of $\mathrm{Cu}$ layer was required for successful leveling.

\section{Acknowledgments}

This work was supported by KOSEF through the Research Center for Energy Conversion and Storage (RCECS) and by the Institute of Chemical Processes (ICP).

Seoul National University assisted in meeting the publication costs of this article.

\section{References}

1. D. Josell, D. Wheeler, W. H. Huber, and T. P. Moffat, Phys. Rev. Lett., 87, 016102 (2001).

2. D. Josell, D. Wheeler, C. Witt, and T. P. Moffat, Electrochem. Solid-State Lett., 6, C143 (2003).

3. A. C. West, S. Mayer, and J. Reid, Electrochem. Solid-State Lett., 4, C50 (2001)

4. C. Yu and J. O. Dukovic, Abstract 168, The Electrochemical Society Meeting Abstracts, Vol. 2004-1, San Antonio, TX, May 9-13, 2004.

5. J. Reid, E. Webb, J. Sukamto, Y. Takada, and T. Archer, Abstract, 148, The Electrochemical Society Meeting Abstracts, Vol. 2004-1, San Antonio, TX, May 9-13, 2004.

6. B. B. Stickney, B. Nguyen, B. Basol, C. Uzoh, and H. Talieh, Solid State Technol., 46, 49 (2003).

7. O. Kardos, H. B. Durham, A. J. Tomson, and D. A. Arcilesi, U.S. Pat. 3,542,655 (1970).

8. O. Kardos, D. A. Arcilesi, A. J. Tomson, and S. P. Valayil, U.S. Pat. 3,682,788 (1972).

9. J. A. D. Jensen, P. Moller, T. Bruton, N. Mason, R. Russell, J. Hadley, P. Verhoeven, and A. Matthewson, J. Electrochem. Soc., 150, G49 (2003).

10. M. X. Yang, D. Mao, C. Yu, J. Dukovic, and M. Xi, Solid State Technol., 46, 37 (2003).

11. S.-M. Jang, U.S. Pat. 6,350,364 (2000)

12. S.-K. Kim, S. Hwang, S. K. Cho, and J. J. Kim, Electrochem. Solid-State Lett., 9, C25 (2006).

13. C.-F. Chen and K.-C. Lin, Jpn. J. Appl. Phys., Part 1, 41, 1981 (2002).

14. I. S. Zavarine, O. Khaselev, and Y. Zhang, J. Electrochem. Soc., 150, C202 (2003).

15. J. P. Healy and D. Pletcher, J. Electroanal. Chem., 338, 155 (1992).

16. T. P. Moffat, D. Wheeler, and D. Josell, J. Electrochem. Soc., 151, C262 (2004).

17. S.-K. Kim, S. K. Cho, J. J. Kim, and Y.-S. Lee, Electrochem. Solid-State Lett., 8, C19 (2005).

18. J. O. Dukovic, IBM J. Res. Dev., 34, 693 (1998). 